\title{
STUDI BUDIDAYA KEPITING SOKA (Soft Crab) DI TAMBAK TRADISIONAL PULAU TARAKAN KALIMANTAN UTARA
}

\section{AQUACULTURE STUDY OF SOFT MUD IN TRADISIONAL POND IN TARAKAN ISLAND NORTH KALIMANTAN}

\author{
Heppi Iromo ${ }^{1)}$, M. Amien ${ }^{2)}$, Suliadi ${ }^{3)}$ \\ 1,2,3) Program Studi Budidaya Perairan Fakultas Perikanan dan Ilmu Kelautan \\ Universitas Borneo Tarakan \\ Jalan Amal Lama Nomor 1, Tarakan \\ Email: ${ }^{1}$ sholatdhuha4rakaat@gmail.com
}

\begin{abstract}
ABSTRAK
Teknologi budidaya kepiting soka belum banyak diketahui oleh masyarakat. Hal ini yang menjadi ketertarikan peneliti untuk melakukan kajian tentang budidaya kepiting soka di beberapa lokasi budidaya yang berkembang di Tarakan. Tujuan dari penelitian ini untuk menggali informasi tentang beberapa beberapa teknik budidaya kepiting soka di Pulau Tarakan Kalimantan Utara. Metode Penelitian yang digunakan adalah metode deskriptif dengan menggunakan metode survei, dengan pengumpulan data primer dan data sekunder. Data primer meliputi data yang diperoleh melalui sampling, pengukuran, pengamatan dan wawancara. Data sekunder meliputi data penelitian atau kajian yang dipublikasikan secara umum. Komponen data yang dibutuhkan dalan penenlitian ini terdiri atas beberapa parameter antara lain; Luas lahan yang digunakan, sumber bibit kepiting, cara memilih bibit, Jumlah kebutuhan bibit, dan teknik budidaya kepiting soka serta beberapa parameter kualitas air. Hasil penelitian menunjukkan bahwa budidaya kepiting soka di pulau Tarakan menggunakan dua teknik pemotongan organ (multilasi) pada kepiting yaitu pemotongan kaki jalan saja dan pemotongan kaki jalan dan kaki renang. Hasil budidayanya masih menunjukkan tingginya kematian pada kepiting soka yang disebabkan stress pada bibit.
\end{abstract}

\section{Kata Kunci : Kepiting soka, tambak tradisional}

\begin{abstract}
The technology of soft mud crab cultivation has not been widely known by the public. This is the interest of researchers to conduct a study of the cultivation of soft mud crabs in several developing cultivation locations in Tarakan. The purpose of this study was to explore information about several techniques for soft mud crab cultivation in Tarakan Island, North Kalimantan. The research method used is descriptive method using the survey method, by collecting primary data and secondary data. Primary data includes data obtained through sampling, measurement, observation and interviews. Secondary data includes research data or studies that are publicly published. The data components needed in this study consist of several parameters including; The area of land used, the source of crab seeds, how to choose seeds, the number of seed requirements, and the technique of soft mud crab cultivation as well as some water quality parameters. The results showed that the cultivation of soka crabs on Tarakan island used two techniques of organ cutting (multilation) on crabs, namely cutting the legs of the road only and cutting the road legs and swimming feet. The cultivation results still show the high mortality of soft mud crabs caused by stress on seedlings.
\end{abstract}

Keywords: Soft Mud Crab, Tradisional Ponds

\section{PENDAHULUAN}

Kepiting Bakau (Scylla $s p$ ) merupakan salah satu komoditas perikanan yang dominan di
Indonesia yang hidup di hutan bakau (mangrove). Kepiting merupakan salah satu diantara komoditas perikanan yang diminati 
oleh masyarakat baik dari kalangan pembudidaya tambak, pengusaha maupun konsumen.

Pulau Tarakan merupakan salah satu pulau di Provinsi Kalimantan Utara yang memiliki luas sekitar $250 \mathrm{~km}^{2}$ dan sebagian besar pesisirnya masih ditumbuhi oleh hutan mangrove. Pada Pulau Tarakan terdapat usaha budidaya kepiting bakau yang salah satunya adalah budidaya kepiting soka (soft crab). Budidaya kepiting soka banyak berkembang di Pulau Tarakan, namun hingga saat ini teknologi budidaya kepiting soka belum banyak diketahui oleh masyarakat. Hal ini yang menjadi ketertarikan peneliti untuk melakukan kajian tentang budidaya kepiting soka di beberapa Iokasi budidaya yang berkembang di Tarakan.

Tujuan dari penelitian ini untuk menggali informasi tentang beberapa beberapa teknik budidaya kepiting soka di Pulau Tarakan Kalimantan Utara.

\section{METODE PENELITIAN}

Penelitian ini dilakukan di beberapa lokasi tambak tradisional yang terdapat di Pulau Tarakan. Lokasi tambak tradisional tersebut merupakan bekas tambak budidaya udang windu yang kurang produktif dan berada di Kampung Empat, Pamusian dan Karang Anyar Pantai.

Metode Penelitian yang digunakan adalah metode deskriptif dengan menggunakan metode survei, dimana hasil penelitian akan menggambarkan sifat dari suatu keadaan. Dalam upaya menunjang akurasi hasil penelitian dilakukan pengumpulan data primer dan data sekunder. Data primer meliputi data yang diperoleh melalui sampling, pengukuran, pengamatan dan wawancara. Data kualitas air hasil diambil secara in situ melalui pengukuran secara langsung di lapangan dan secara ex situ melalui pengukuran dan analisis di laboratorium. Data sekunder meliputi data penelitian atau kajian yang dipublikasikan secara umum. Komponen data yang dibutuhkan dalan penenlitian ini terdiri atas beberapa parameter antara lain; Luas lahan yang digunakan, sumber bibit kepiting, cara memilih bibit, Jumlah kebutuhan bibit, dan teknik budidaya kepiting soka serta beberapa parameter kualitas air.

\section{HASIL DAN PEMBAHASAN}

Lokasi budidaya kepiting soka yang di gunakan dalam penelitian berada di Pulau Tarakan dan merupakan bekas tambak udang windu yang tidak produktif lagi. Tambak tersebut umumnya berbentuk tidak beraturan dan memiliki luas sekitar \pm 1-2 Ha. Lokasi budidaya kepiting soka di Pulau Tarakan sudah memiliki akses jalan yang baik sehingga kendaraan dapat keluar masuk ke area tambak dengan mudah, hal ini akan mempermudah proses pengiriman hasil panen kepiting soka ke pengepul atau ke perusahaan yang akan membeli hasil panen kepiting soka.

\section{Luas Lahan Budidaya}

Berdasarkan hasil penelitian pada beberapa lokasi tambak budidaya kepiting soka di pulau Tarakan, di dapatkan data luas lahan tambak dan kepemilikian crab box sebagai wadah budidaya kepiting soka sebagai berikut :

Tabel 1. Luas Lahan Tambak Budidaya Kepiting Soka

\begin{tabular}{|l|c|c|c|c|}
\hline No & Nama pemilik & Lokasi & Luas lahan & Jumlah crab box \\
\hline 1 & Rusli & Kampung 4 & $\pm 1 \mathrm{Ha}$ & 15.000 buah \\
2 & Amin & Mulawarman & $\pm 2 \mathrm{Ha}$ & $15.000 \mathrm{buah}$ \\
3 & Seni & Boom Panjang & $\pm 2 \mathrm{Ha}$ & $25.000 \mathrm{buah}$ \\
\hline
\end{tabular}

Berdasarkan Tabel 1. terlihat bahwa lahan yang digunakan untuk budidaya kepiting soka sangat luas berkisar antara \pm 1-2 $\mathrm{Ha}$. Luasan lahan ini tidak dimanfaatkan secara optimal karena keterbatasan wadah crab box dan bibit kepiting soka.

\section{Sumber Bibit Kepiting}

Berdasarkan hasil penelitian yang didapatkan informasi bahwa bibit kepiting soka yang diperdagangkan berasal dari penangkapan di alam. Hasil penangkapan secara kualitas dan kuantitas agak sulit di andalkan. Kualitasnya 
akan berkurang kalau bibit yang ditangkap berasal dari penangkapan di tambak yang tidak langsung di jual ke pasar tetapi ditampung sementara. Kuantitas sulit dijaga karena akan selalu berkurang baik ukuran maupun jumlah.
Bibit kepiting yang digunakan didapatkan dari berbagai sumber seperti UD. Global dan MSR. UD. Global yang berlokasi di pasar Beringin Tiga dan MSR yang berlokasi di Jembatan Besi (Tabel 2).

Tabel 2. Sumber dan Harga Bibit Kepiting Bakau

\begin{tabular}{|l|l|l|}
\hline No & \multicolumn{1}{|c|}{ Sumber bibit } & Harga bibit (Rp) \\
\hline 1 & UD. Global & $16.000-18.000 / \mathrm{kg}$ \\
2 & MSR & $16.000-18.000 / \mathrm{kg}$ \\
\hline
\end{tabular}

Bibit kepiting dijual pada harga Rp 16.000 sampai dengan $\mathrm{Rp} 18.000 / \mathrm{kg}$ kepada para pembudidaya kepiting soka. Bibit kepiting ini didatangkan dari pulau Tarakan dan daerah luar Tarakan seperti pulau Tias, dan Mangkudulis yang termasuk dalam wilayah Kabupaten Nunukan.

\section{Proses Memilih Bibit}

Ada beberapa hal yang diperhatikan para petambak dalam memilih bibit kepiting yang dikatakan sehat seperti, bagian tubuhya lengkap, dan bergerak aktif. Kesehatan bibit haruslah diperhatikan karena kesehatan bibit merupakan salah satu faktor penunjang keberhasilan budidaya kepiting soka, bibit yang sehat dapat dilihat dari gerakannya yang gesit, bagian tubuhnya lengkap dan bibit kepiting yang kurang sehat warna karapasnya akan kemerah-merahan dan pudar serta pergerakannya lamban.

Dalam pemilihan bibit petambak juga memperhatikan bobot kepiting yang akan dibelinya. Petambak budidaya kepiting soka selalu memilih bibit dengan bobot berkisar antara 80 gram sampai dengan 150 gram. Petambak beralasan dengan menggunakan bibit dengan berat 80 gram sampai 150 gram, proses moultingnya lebih cepat dari pada menggunakan bibit dengan berat yang lebih dari 150 gram. Hal ini diduga karena pada bobot sekitar 80-150 gram merupakan bobot kepiting muda yang proses moultingya lebih cepat. Selain itu pada bobot tersebut secara umum kepiting belum masuk katagori induk yang tidak akan moulting. Hal ini sesuai dengan pendapat Sulaeman, (2006) bahwa pergantian kulit kepiting pada ukuran yang lebih kecil biasanya lebih cepat, maka pengembangan soka biasanya diarahkan untuk kepiting muda dengan bobot 60-150 gram/ekor.

Bibit kepiting yang digunakan semuanya berjenis kelamin jantan. Pengunaan kepiting berjenis kelamin jantan bertujuan agar tidak digunakan kepiting betina sebagai bibit karena dikhawatirkan kepiting betina yang memiliki ukuran sekitar 150 gram telah berkembang telurnya dan kepiting betina yang sedang bertelur tidak akan moulting. (Iromo, 2012).

\section{Kebutuhan Bibit Setiap Periode}

Dari hasil penelitian yang telah di lakukan di tambak budidaya kepiting soka di pulau Tarakan. Didapatkan data jumlah crab box yang dimiliki oleh para pembudidaya kepiting soka sebagai berikut :

Tabel 3. Jumlah Crab Box Yang Dimiliki Pembudidaya Kepiting Soka

\begin{tabular}{|l|l|l|c|}
\hline No & Nama pemilik & Lokasi & Jumlah crab box \\
\hline 1 & Pak Rusli & Kampung 4 & 15.000 \\
2 & Pak Amin & Mulawarman & 15.000 \\
3 & Pak Seni & Bom panjang & 25.000 \\
\hline
\end{tabular}

Kebutuhan bibit kepiting setiap periodenya berbeda - beda pada setiap petambak, hal ini dipengaruhi oleh perbedaan jumlah crab box kepiting soka yang dimiliki. Semakin banyak crab box yang dimiliki maka bibit yang di gunakan bisa semakin banyak, begitu pula sebaliknya. Tetapi akhir-akhir ini ketersediaan bibit kepiting semakin sedikit sehingga 
pembudidaya kepiting soka hanya dapat menggunakan setengah dari jumlah crab box yang dimilikinya untuk budidaya kepiting soka. Dari hasil penelitian yang telah di lakukan di tambak budidaya kepiting soka di dapatkan data jumlah kebutuhan rata-rata bibit kepiting untuk setiap periodenya dapat dilihat pada Tabel 4.

Tabel 4. Jumlah Kebutuhan Rata-Rata Bibit Per Periode

\begin{tabular}{|l|l|l|r|}
\hline No & Nama pemilik & Lokasi & Jumlah bibit \\
\hline 1 & Pak Rusli & Kampung 4 & 11.340 ekor \\
2 & Pak Amin & Mulawarman & 9.450 ekor \\
3 & Pak Seni & Bom panjang & 7.560 ekor \\
\hline
\end{tabular}

Berdasarkan jumlah crab box yang di miliki, pembudidaya membutuhan bibit kepiting berkisar antara 15.000 sampai 25.000 ekor perperiode. Namun kenyataan di lapangan berbeda, ketersediaan bibit yang terbatas menyebabkan pembudidaya tidak dapat memenuhi kebutuhan bibit kepiting.

Kebutuhan bibit kepiting pada setiap lokasi budidaya bervariasi hal ini disebabkan oleh beberapa hal, diantaranya adalah ketersedian bibit yang tidak mencukupi kebutuhan pembudidaya. Bibit yang berasal dari tangkapan di alam tidak dapat mencukupi kebutuhan bibit kepiting soka yang sangat banyak.

\section{Teknik Budidaya Kepiting Soka}

Dari hasil penelitian yang telah dilakukan di tambak budidaya kepiting soka di pulau Tarakan bahwa budidaya yang dilakukan secara umum menggunakan teknik pemotongan sebagian organ pada bibit yang akan digunakan. Pada teknik pemotongan sebagian organ yang digunakan terdapat perbedaan dari ketiga responden. Mengenai budidaya kepiting soka dengan teknik pemotongan sebagian organ pada budidaya kepiting soka yang ada di Tarakan dapat dilihat pada Tabel 5.

Tabel 5. Teknik Budidaya Kepiting Soka.

\begin{tabular}{|l|l|l|l|}
\hline No & Nama pemilik & \multicolumn{1}{|c|}{ Teknik budidaya } & Lokasi \\
\hline 1 & Pak Rusli & Potong kaki jalan dan kaki renang & Kampung 4 \\
2 & Pak Amin & Potong kaki jalan & Mulawarman \\
3 & Pak Seni & Potong kaki jalan dan kaki renang & Boom Panjang \\
\hline
\end{tabular}

Proses pemotongan bertujuan agar kepiting dapat segera moulting atau berganti cangkang. Pemotong kaki kepiting dilakukan menggunakan gunting. Pada ketiga lokasi tambak budidaya kepiting soka didapati perbedaan bagian tubuh kepiting yang dipotong. Pada tambak milik pak Rusli bagian tubuh kepiting yang di potong adalah ketiga pasang kaki jalan dan sepasang kaki renang, sedangkan pada tambak pak Amin bagian tubuh kepiting yang di potong adalah ketiga pasang kaki jalan, dan pada tambak milik pak Seni bagian tubuh kepiting yang di potong adalah ketiga pasang kaki jalan dan sepasang kaki renangnya.
Tujuan dari pemotongan kaki jalan atau kaki renang yang dilakukan oleh pembudidaya kepiting diduga adalah untuk merangsang kepiting agar segera moulting. Hal ini diduga bahwa dengan proses penghilangan atau pemotongan sebagian organ tubuh secara bersamaan dapat merangsang hormon pertumbuhan untuk memacu moulting pada kepiting. Menurut (Affandi dan Tang, 2002) bahwa mematahkan atau memotong kaki jalan kepiting, maka hormon pertumbuhannya akan memacu pembentukan kembali dari anggota badannya yang hilang.

\section{Angka Kelangsungan Hidup (Survival Rate)}


Berdasarkan hasil penelitian tentang ratarata kelangsung hidup kepiting soka perperiode dari ketiga petambak di tambak tradisional tersajikan pada Tabel 6.

\section{Tabel 6. Rata-Rata Nilai Kelangsungan Hidup Kepiting Soka di Tambak Tradisional}

\begin{tabular}{|l|l|l|c|}
\hline No & Nama pemilik & \multicolumn{1}{|c|}{ Lokasi } & Nilai SR \\
\hline 1 & Pak Rusli & Kampung 4 & $\mathbf{6 4} \%$ \\
2 & Pak Amin & Mulawarman & $\mathbf{6 1} \%$ \\
3 & Pak Seni & Boom Panjang & $\mathbf{5 9 \%}$ \\
\hline
\end{tabular}

Nilai kelangsungan hidup kepiting kepiting soka yang dibudidayakan dari ketiga lokasi tersebut tidak terlalu berbeda. Persentasi kelangsungan kepiting masih katagori cukup yaitu berkisar antara 59-64\%. Masih rendahnya kelangsungan hidup kepiting diduga karena bibit yang digunakan berasal dari hasil penangkapan yang kondisinya banyak yang stress karena perlakuan. Bibit berasal dari penangkapan di sekitar tambak tradisional yang ditampung sementara sebelum datang pengumpul. Inilah salah satu penyebab kematian bibit dimana sudah dalam kondisi stress masih dihilangkan atau dipotong lagi organnya.

Mengenai lama waktu pemeliharaan bibit kepiting hingga menjadi kepiting soka rata-rata sekitar yaitu 2 minggu atau 14 hari, sejak dari awal bibit di masukkan kedalam crab box. Ini menunjukkan bahwa perlakuan pemotongan organ yang berbeda dalam teknik budidaya kepiting soka tidak memberikan perbedaan yang nyata baik mengenai lama pemeliharaan maupun persentase kehidupannya.

Dari ketiga tambak budidaya kepiting soka yang berada di pulau Tarakan ternyata petambak hanya memberi perawatan pada media budidaya kepiting soka dengan cara sirkulasi air, mengikuti pasang surut tertinggi, dan biasanya dilakukan sebanyak 2 minggu sekali. Penambahan air tambak ketika terjadi pasang besar dan di lakukan pengurangan air tambak saat air laut mulai surut. Kelebihan dari sirkulasi air dengan pasang surut adalah karena cukup hanya mengandalkan teknis pekerjaan memasukkan-mengeluarkan air melalui pintu air saja serta dalam sirkulasi ini dapat diperoleh debit dan volume air dalam jumlah yang relatif besar dalam waktu yang lebih singkat.
Berdasarkan hasil pengukuran suhu pada tambak tradisional di pulau Tarakan pada siang berkisar $23{ }^{\circ} \mathrm{C}-24{ }^{\circ} \mathrm{C}$, pada sore hari dengan kisaran $24{ }^{\circ} \mathrm{C}-26{ }^{\circ} \mathrm{C}$. Kisaran suhu yang terdapat di tambak tradisional masih dalam kisaran yang baik untuk budidaya kepiting bakau atau kepiting soka. Hal ini juga di dukung dengan pendapat Iromo $d k k$, (2018) suhu optimal untuk kepiting di tambak tradisional adalah $22{ }^{\circ} \mathrm{C}-36{ }^{\circ} \mathrm{C}$. Berdasarkan hasil pengukuran $\mathrm{pH}$ pada tambak tradisional di pulau Tarakan. Diperoleh pH dengan kisaran 67 dan kisaran ini masih dapat dikatakan baik untuk media budidaya kepiting soka karena menurut Iromo $d k k$, (2018) derajat keasaman dalam media budidaya kepiting di dalam tambak tradisional sebaiknya di pertahankan antara 6,0-8,0. Hasil pengukuran DO pada tambak budidaya kepiting soka berkisar 5 6,51 . Dari hasil pengukuran DO yang dilakukan selama penelitian, DO pada tambak taradisional di pulau Tarakan di katakan ideal untuk pertumbuhan kepiting bakau. Menurut (Affandi dan Tang, 2004) menyatakan kepiting cangkang lunak dapat di budidayakan dalam kondisi perairan teduh dengan air yang memiliki DO > 2 ppm. Pengukuran salinitas ditambak budidaya kepiting soka berkisar antara 22 ppt - 25 ppt. Salinitas ini masih termasuk baik untuk pemeliharaan soka. Hal ini sesuai dengan pendapat Iromo $d k k$, (2018) bahwa salinitas ditambak tradisional di pPulau Tarakan berkisar antara 10-20 ppt. Menurut pendapat Ramelan (1994) dalam Agus (2008) kepiting akan mengalami pertumbuhan yang lambat jika salinitas berkisar antara 35 - 40 ppt, dan tumbuh dengan baik pada salinitas $10-15$ ppt, tetapi lebih sensitif terhadap serangan penyakit. 


\section{KESIMPULAN}

1. Budidaya kepiting soka di Tarakan masih menggunakan Teknik teknik mutilasi atau pemotogan bagian tubuh kepiting.

2. Terdapat dua teknik pemotongan (multilasi) pada kepiting yaitu pemotongan kaki jalan saja dan pemotongan kaki jalan dan kaki renang.

3. Masih tingginya kematian pada budidaya kepiting soka disebabkan perlakuan sumber bibit yang kurang baik

\section{DAFTAR PUSTAKA}

Anonimous, 2004. Cangkang Lunak Terobosan Anyar Dongkrak Harga Kepiting. Trobos No. 62. Nov, 2004. Tahun ke-VI, Jakarta.

Affandi, dan Tang, U. 2002. Fisiologi Hewan Air.Universitas Riau Prees.Riau. hal. 217.

Agus, M. 2008. Analisis Carryng Capacity Tambak pada Sentra Budidaya Kepiting Bakau (Scylla Sp). Pemalang.

Aslamyah S., Yushinta Fujaya. 2010. Stimulasi Molting dan Pertumbuhan Kepiting Bakau (Scylla sp.) Melalui Aplikasi Pakan Buatan Berbahan Dasar Limbah Pangan yang Diperkaya dengan Ekstrak Bayam. Jurnal Ilmu Kelautan Vol. 15 (3) 170178

Chang E S., D L Mykles. 2011. Regulation of cruatacea molting: Areview and our perspectives. Gen. Comp. Endocrinol., $172: 323-330$

Effendie, M.I. 1997. Budidaya Perikanan. Yayasan Pustaka Nusantara Press.Yogyakarta.

Fujaya, Y, Siti, A, Letty, F dan Nur, A. 2012. Budidaya dan Bisnis Kepiting Lunak, Stimulasi Moulting dengan Ekstrak Bayam. Brilian Internasional. Surabaya 109 hal.

Hidayanto, M., H.W. Agus, dan F. Yossita., 2004. Analisis Tanah Tambak sebagai Indikator Tingkat Kesuburan Tambak. Jurnal Pengkajian dan Pengembangan Teknologi Pertanian. Vol. 6, No. 4, (98109) tahun 2004. Badan Riset Pertanian, Departemen Pertanian Indonesia.

Iromo H, N. Fariza dan M. Amien.H. 2012. Konservasi Induk Betina Kepiting Bakau Matang Gonad DiPulau Tarakan Kalimantan Timur. Prosiding Seminar
Nasional Ke-II Hasil-Hasil Penelitian Perikanan Dan Kelautan Semarang

Iromo H., A Jabarsyah and Awaluddin. 2018. Reproduction of females mud crab (Scylla serrata) with thyroxine hormone supplementation in traditional ponds from north borneo Indonesia. International Journal of Fisheries and Aquatic Studies 2018; 6(3): 378-381

Jabarsyah A., Heppi Iromo dan U. Arif. 2009. Laju Pertumbuhan Kepiting Bakau (Scylla Serrata) Dengan Pemberian Jenis Bahan Pakan Yang Berbeda. Jurnal Harpodon Vol 8 (4);61-71.

Kasry, K. 1996. Budidaya Kepiting Bakau Dan Biologi Ringkas. Bhatara Press, Jakarta.

Kanna, I. 2002. Budi Daya Kepiting Bakau Pembesaran dan Pembenihan. Kanisius Press. Yogyakarta. $80 \mathrm{hlm}$.

Keenan C. P. 1999. The fouth spesies of scylla. dalamMud crab aquaculture and biology. ACIAR proceedings. 78. ACIAR. Canberra. $48-58$.

Kuntiyo, arifin, Z, dan Supratomo, T. 1994. Pedoman Budidaya Kepititng Bakau (Scylla serrata) Di Tambak, Direktorat Jendral, Balai Budidaya Air Payau, Jepara, $29 \mathrm{hlm}$.

Nasikin, A. 2003. Analisis Kelayakan Usaha Penggemukan Kepiting Bakau (Scylla serrata) Dalam Keramba di Desa Kupang Kecamatan Jabon, Kabupaten Sidoarjo, Jawa Timur. Universitas Brawijaya Fakultas Perikanan, malang (tidak dipublikasikan).

Nontji, A. 2002. Laut Nusantara. Penerbit Djambatan Press. Jakarta.

Prianto, E. 2007. Peran Kepiting Sebagai Spesies Kunci (Keystone Spesies) pada Ekosistem Mangrove. Prosiding Forum Perairan Umum Indonesia IV. Balai Riset Perikanan Perairan Umum. Banyuasin.

Sara, L. et all 2006. Abundance and Distribution Patterns of Scylla spp. Larvae in the Lawele Bay, Southeast Sulawesi, Indonesia, Journal Asian Fisheries Science, journal, Vol. 19; 331-347.

Susanto, H. 1990. Budidaya Ikan Di Pekarangan. Penerbit Penebaran Swadaya.Jakarta.

Turano, M.J., R.J. Borski \& H.V. Daniels, 2007. Compensatory growth of Pond-reared Hybrid Striped Bass, Morone chrysops $x$ Morone saxatilis, Fingerling, Journal of the World Aquaculture Society, 38 (2): 250261. 
